\title{
In-season plot area loss and implications for yield estimation in smallholder rainfed farming systems at the village level in Sub-Saharan Africa
}

\author{
Ibrahim Wahab
}

Published online: 28 June 2019

(C) The Author(s) 2019

\begin{abstract}
The shortfalls in the quality, quantity, and reliability of agriculture performance data are neither new nor confined to Sub-Saharan Africa (SSA). It is, however, a more dire challenge given the overwhelming importance of agriculture in the economies of most countries in the region in terms of food security and poverty reduction. While farmers' self-reported (SR) data on crop outputs and farm sizes remain popular variables for computing plot productivity and yields, especially in SSA, other methods such GPS measurement and remote sensing measurement of crop area, crop cuts (CC) as well as whole plot harvests have been touted as the gold standard methods for yield measurement. All these approaches to yield estimation are insufficient in capturing real agriculture productivity in rainfed farming systems due to the significant area loss that characterizes these farming systems in the course of each cropping season. This paper compares yield data of smallholder maize plots from two farming communities in the Eastern Region of Ghana based on farmer self-reported outputs and crop cuts, as well as GPS and aerial imagery measurement of plot area. The study finds a high level of agreement between GPS-measured plot area and that measured using remote sensing methods $\left(\mathrm{R}^{2}=0.80\right)$ with the minor deviations between the two measures
\end{abstract}

I. Wahab $(\bowtie)$

Department of Human Geography, Lund University, Solvegatan 10, 22362 Lund, Sweden

e-mail: ibrahim.wahab@keg.lu.se attributable to changes in farmers' plans in the course of the season with regards to their cultivation extent. More interestingly, the study finds a substantial disparity between measured CC yields and SR yields; $2174 \mathrm{~kg} / \mathrm{ha}$ for CC yields compared to $651 \mathrm{~kg} / \mathrm{ha}$ for SR yields. The significant disparity between the two measures of yield is partly attributable to the significant intra-plot variability in crop performance leading to plot area loss in the course of the season. This area loss (ranging from 15 to $30 \%$ of the planted area) is usually not taken into account in current yield measurement approaches. Delineating the productive and planted-but-unproductive sections of plots has important implications not only for yield estimation methodologies but also for shedding more light on the factors underlying current poor yields and pathways to improving productivity on smallholder rainfed maize farms.

Keywords Smallholder farming - Agricultural productivity $\cdot$ Farm yield measurements $\cdot$ Remote sensing

\section{Introduction}

Globally, food crop production and productivity have significantly grown in the last half-century. There is, however, the need for this growth to continue in the 
coming decades to meet expected increases in demand. Unlike other regions of the world, these increases have been largely driven by cropland expansion rather than yield growth on currently cropped lands. Continued reliance on crop area expansion is, however, unsustainable in the long term with human population and energy requirements set to rise even further in the next several decades. This is so because many countries are now facing land scarcity with the most fertile areas having, generally, already been put in use. Expansion into more marginal lands increases the risk of further land degradation. The majority of farmers have small farms (1-5) ha and limited chances to expand their farms. Thus, increasing productivity in a sustainable manner can be a way out of poverty at the same time as it can create surpluses for the markets. A fundamental requirement for achieving Goal 2 (Zero hunger) of the Sustainable Development Goals, particularly for SSA, is thus significant improvements in farm productivity. While the agricultural landscapes of much of Europe, North America and some parts of Asia have experienced significant changes in the area of agricultural intensification and mechanization in the last century, same cannot be written of SSA. The latter region is still dominated by smallholder farms ${ }^{1}$ cultivated under rainfed regimes (De Graaff et al. 2011), using predominantly non-mechanized methods and tools (Sheahan and Barrett 2017). Given the pervasiveness of smallholder systems and their importance in poverty reduction and food security not just in the agricultural sector but also the wider economies of SSA countries (Wiggins 2009; World Bank 2008), their productivity ought to be the preoccupation of research and development policy. Though doubling agricultural productivity by 2050 has rightly been the

\footnotetext{
1 There is no globally accepted definition of smallholder farms, often used interchangeably with small farms and family farms. Usually defined based on certain criteria: landholding size, resource endowment, production orientation and tools, source of farm labour, asset base, and level of vulnerability (Lipton 2005; Samberg et al. 2016; World Bank 2003). All these criteria need not be simultaneously met for a farm to qualify as such (Hagos and Geta 2016). In the present study and in the Ghana context (MoFA-SRID 2017; SRID-MoFA 2013), smallholder farms occupy less than 2 hectares, have poor resource endowment, subsistence production orientation using predominantly rudimentary tools, high dependence on farm household labour, low level of external inputs use, poor asset base, and high level of vulnerability.
}

clarion call among researchers and development practitioners, obtaining accurate and reliable data on smallholder productivity, a sine qua non for formulating informed policies that adequately cater for the oft-reported poor yields among smallholder farmers in SSA has not garnered adequate attention.

Currently, the most reliable sources of agriculture performance data at the global level are the statistical databases of the Food and Agriculture Organization of the United Nations and that of the World Bank Group. These databases are, in turn, based on data from general-purpose as well as agriculture-specific surveys usually conducted by national statistical services. It is based on these sources that regional and national agricultural productivity comparisons are often made. While such analysis and comparisons are useful for understanding temporal trends, there are important peculiarities, to be shown later, within various regions and villages which underlie the reported data and thus need a more nuanced understanding. These broad comparisons often form the basis of certain misconceptions about crop productivity in SSA. Smallholder farming in this region is still characterized by significant crop yield variability and this variability is persistent even within the same agroecological zones and farm plots (Falconnier et al. 2016; Ronner et al. 2016). Waddington et al. (2010) point out that there is a general tendency to average out the constraints over villages and farming systems, arguing for the need to not only recognize but also take into account differences in farming practices and growing conditions.

In terms of justification for this study, unlike other regions, farm productivity in SSA is inextricably linked to the food security of smallholders and their households and so yield estimation methods developed and tested in other regions may not adequately capture agricultural productivity in SSA (Sapkota et al. 2016). Reynolds et al. (2015), in explaining the variability in yields, point out that, sometimes, the top $5 \%$ could yield as much as 4 times the median yield, and argue that while this could point to the so-called yield gaps, it may as well suggest shortfalls in current measures for tracking national and plot productivity. This recognition ought to feed into how crop yields are measured in different regions rather than seeking to make data comparable across regions and in the process lose out on the nuances of SSA agriculture performance. To this end, the present paper seeks to demonstrate the complexities associated with the 
estimation of yields on smallholder farms and discuss how within-plot heterogeneity could impact yield measurement variables. The paper will, thus, contribute to current efforts at improving methods of measuring agricultural productivity by highlighting the within- and between-plot variabilities and the insufficiency of current approaches of yield measurement. It will also show how this can be improved by complementing field-based measures of crop cuts, GPS area and farmer self-reported outputs with remotely-sensed UAV data to enhance the accuracy of yield data. That smallholder farms in SSA perform poorly compared to other regions is trite knowledge. However, getting a more accurate representation of yield levels is crucial for understanding the productivity of this critical sector of the economies of most SSA countries. We seek to achieve this by demonstrating how current yield measurement approaches inadequately capture plot level productivity given the substantial heterogeneity characteristic of these farming systems. This is done using remote sensing data from a UAV and demonstrates how this integration could potentially improve the accuracy of agriculture yield data for such complex farming systems.

\section{Literature review}

Yield levels and variability: from global to local

The concept of crop yield measures refers to the measurement of the productivity of a plot; i.e. the quantity of a crop produced from specified plot area. It is the outcome of a season-long production process on the farm and as such, it is the ultimate objective of the farmer (Beddow et al. 2015). The key variables for determining crop yields are crop area and crop production (World Bank 2010), though the use of other inputs in the production process means that yield is at best a partial measure of farm productivity (Beddow et al. 2015). Fermont and Benson (2011) therefore define crop yield as a ratio of harvested crop output and crop area. They (Fermont and Benson) point out that despite the apparent simplicity of this formula, the estimation of both variables for computing crops yields is ridden with several difficulties (discussed in next section).

Stabilization of crop yields through the reduction of inter-annual and inter-farm yield variability is crucial to the food systems of nations (Ben-Ari and Makowski 2014; Kassie et al. 2014; Ray et al.2015) and this is particularly true for marginal production regions in SSA where most smallholder farmers are still net buyers of food. ${ }^{2}$ There are two main perspectives from which yield variability can be analysed: (a) temporal yield variability; and (b) spatial yield variability. Temporal (inter-annual) yield variability refers to that which occurs over time and is largely attributed to differences in growing conditions, chiefly climate though it is also significantly impacted by other factors like production technologies. Spatial variability of yields refers to that which occurs over space even when biophysical factors are controlled for. It is this type of variability that is of more interest with regards to dealing with production shortfalls and can be assessed at various scales from the global through regional, national and even subnational levels.

Even within countries and agroecological regions in Africa, significant spatial yield variabilities have been reported. For instance, Falconnier et al. (2016) found significant maize yield variability in southern Mali, a range of 0.20-5.24 tons/ha on unaltered control plots. Similarly, in seeking to evaluate the impact of fertilizers and leguminous plants on subsequent maize crops in Rwanda, Rurangwa et al. (2018) found that maize yields ranged from 0.8 tons/ha in controls to 6.5 tons/ha in treatments previously fertilized with phosphate and planted after common beans, and from 1.9 tons/ha in controls to 5.3 tons/ha for maize grown after soybean. Based on the Ugandan National Household Survey data, Fermont and Benson (2011) estimated that average unfertilized maize yields for local and improved maize varieties ranged from 0.7 to 1.7 tons/ ha, and 1.1 to 2.9 tons/ha, respectively, with fertilizer use increasing on-farm trial yields to between 4.3 and 4.5 tons/ha. The above point to significant maize yield variability even within the same agro-ecological zones. In order to stabilize and improve yields to meet projected increases in demand, however,

\footnotetext{
${ }^{2}$ The poorest of the poor in developing countries are smallholder farmers (FAO 2017a). Most of the poor are net buyers of staple food crops (World Bank 2008). In many African countries, the proportion of smallholders categorized as net sellers of maize is estimated to be less than a third of all producers, with most of the smallholders, while often selling some maize soon after harvest to generate cash income, needing to purchase more from the market than they sell in the course of the entire season (FAO 2017a, p. 15).
} 
currently poorly-yielding plots need to be brought up to the levels of better performing plots.

Much of the variability is, often ascribed to differing farm management practices for different plots. Differing management practices, however, do not adequately explain variability which occurs within plots. As Sheahan and Barrett (2017) point out, there is negligible variation in input use (though fertilizer use is a major yield determinant) by farmers within plots. That is, farmers do not discriminate between fertile and non-fertile, or erosion-prone and non-eroding portions of their plots in deciding the location and quantity of fertilizers to apply. This is curious because smallholder farmers' economic rationality is welldocumented in the literature (Beddow et al. 2015; Jirström 1996; Mueller and Binder 2015). Thus, they would not want to dissipate inputs on erosion-prone or obviously unproductive segments of their plots. However, current yield measurement approaches do not cater to these nuances. There is a lack of appreciation and consideration of the intra-plot variations in current approaches to yield measurement, with plots often treated as homogeneous units in spite of significant heterogeneity in smallholder plots in SSA.

Shortfalls of current measures of yield estimation

Debates on the weaknesses of current crop yield estimation approaches became topical in the last decade. This culminated in the Global Strategy: a global, multi-agency initiative under the auspices of the United Nations Statistical Commission in 2010 which identified improvements in the measurement of agricultural productivity as the highest priority of research (FAO 2017b; World Bank 2010). This is a much-needed intervention given the significant advances in technology since the previous comprehensive guideline on yield estimation by the FAO was issued as far back as the 1980s (Carletto et al. 2015; Reynolds et al. 2015). Sapkota et al. (2016) contend that the need for such a revision is starker in the context of smallholder production systems, particularly at the plot, farm, and landscape scales so as to obtain a much-needed accurate agricultural data at these scales. Though shortcomings with agricultural statistics are neither new nor confined to SSA, it is more of a challenge in the sub-region given the predominance of smallholder farms, their linkages to households food security and importance in national economies, as well as the wide range of crops cultivated (Carletto et al. 2015; Fermont and Benson 2011).

Conventionally, yield measurement is based on farmer-reported estimations of cropped area and crop output, though the latter could also be based on the socalled crop cuts or whole plot harvests (Lobell et al. 2018). Most SSA countries, however, still depend on farmer self-reported data for both crop output and plot area to estimate yields. These two main variables used in deriving crop yields can be arrived at using several methods. For crop output, methods include crop modelling (both process-based and empirical crop modelling), allometric models, purchasers' records, crop insurance data, crop cards kept by farmers, expert's assessment, sampling of harvest units, whole plot harvest, grain weighting, crop cutting, farmer surveys and remote sensing approaches (Fermont and Benson 2011; Sapkota et al. 2016). Methods for arriving at the plot area include farmer estimations report, collective estimation by farmers and enumerators, the polygon method of actual area assessment, the rectangulation and triangulation methods, $\mathrm{P}^{2} / \mathrm{A}$ method, GPS area measurement, remote sensing, and GIS methods. All these methods come with various degrees of efficiencies. For the purposes of this paper, we focus on the merits and weaknesses of the farmerreported output, crop cutting, and GPS area measurement due to their wide acceptance and application, and the fact that they form the basis of most yield databases.

\section{Farmer self-reports crop outputs}

Of all the methods for estimating the numerator of yield estimation formula, farmer estimation of crop output is the most widely used and is the main source of data for most agriculture databases in SSA (Fermont and Benson 2011; Sapkota et al. 2016). Its popularity is borne out of its convenience, costeffectiveness, and efficiency as well as its applicability in diverse farming systems. Farmer estimations of crop outputs could either be from predictions - the number of crops farmers expect to harvest at the end of the farming season from a given plot or recall-the quantity they did harvest (Fermont and Benson 2011). For output predictions, visual estimations of crop vigour and yields are most accurate at maximum 
stages of crop growth (Singh 2003; Wahab et al. 2018), and ideally with the farmer and enumerator in visual contact with crops (Fermont and Benson 2011). The reliability of such predictions, however, depends on the previous seasons' experiences of the farmer on the particular plot. Farmer recalls of crop output is however done sometime after harvest either at the residence of the farmer or the storage location of the output to enable cross-checking.

While a number of studies attest to the relatively higher accuracy and lower variability of farmer estimations of crop outputs (Fermont and Benson 2011), and notwithstanding the cost-effectiveness and ease-of-application of this method, there are several weaknesses associated with it. Carletto et al. (2015) assert that farmer estimations are riddled with a high degree of arbitrariness and subjectivity, leading to significant errors. Sources of these errors include the tendency to round off quantities, not accounting for inkind payments to relatives, farm labourers, and landowners, poor recollection of historical outputs, poor quality of responses in prolonged interviews, the tendency to average outputs over several seasons, deliberate under- and over-reporting as well as errors arising from conversions from non-standard units (Fermont and Benson 2011; Gourlay et al. 2017; Sapkota et al. 2016). With regards to errors due to conversion from non-standard units, the maize crop is one of the most susceptible crops. Carletto et al. (2015) posit that significant portions of the total production of maize may be harvested while still green, and particularly in the context of food-insecure communities. They point out that this is a major source of error because not only do most surveys not collect data on such fresh maize harvest, but even those that do have difficulty converting such quantities in an accurate manner.

Additional sources of error for farmer-reported output is the complication that results from intercropping and other crop mixing practices. Again, this is most pronounced in the SSA context where farmers intercrop for a variety of reasons including assurance against total crop failure arising from pests infestation (Yengoh 2012) and a bid to increase output from individual plots (Fermont and Benson 2011). Generally, intercropping would have a negative consequence for the total output of individual crops (Srivastava et al. 2016), even though others have found a symbiotic relationship between nitrogen fixers such as groundnuts and beans, and maize yields (Rurangwa et al. 2018). Either way, taking estimates of crop outputs from farmers without due consideration for the cropping system is likely to underestimate the actual productivity of their plots. Further to this is the need to probe what type of outputs farmers report. Do farmers report gross yields - that which is obtained before any losses during and after harvest or that which they have in storage after postharvest losses as well as in-kind payments for land rental? Owing to these and other inherent shortcomings of the farmerestimated crop outputs, the FAO recommends what is deemed as a more objective method of output measurement: crop cutting (Desiere and Jolliffe 2018; Gourlay et al. 2017).

\section{Crop cuts and whole plot crop harvests}

For the purposes of quantifying crop outputs, particularly for cereals but to a lesser extent, roots, and tubers, crop cutting is often considered the gold standard (Carletto et al. 2015). Since its development in the 1950s in India and subsequent endorsement by the FAO in the 1980s, this method has gained widespread recognition as a more objective method for output and yield measurement. With this method, a subplot or a number of subplots are randomly demarcated using various means and crop outputs from these subplots are harvested by trained field staff, and this then forms the numerator of the yield formula (FAO 2017b; Fermont and Benson 2011). The number and size of subplots generally range between 1 and 5 and 0.5 and $50 \mathrm{~m}^{2}$, respectively, depending on available resources and level of precision desired (Sapkota et al. 2016).

Though it has been touted as more objective, the crop cutting method has its own inherent biases. These biases could be substantial on relatively small, irregularly-shaped plots with uneven plant density (Fermont and Benson 2011): an apt characterization of a substantial proportion of smallholder farms in SSA. Recommendations for dealing with plots with variable crop performance range from increasing the number and size of subplots to using a neutral person-not the researcher, farmer nor the extension officer, and even blindfolding the person selecting subplot (Sapkota et al. 2016). Even with such elaborate precautions to minimize bias and thus, improved reliability, other shortfalls such as edge, border, and harvest effects, 
weighing errors as well as the costly and timeconsuming nature of this method do not endear it to more researchers.

It is on the basis of the shortfalls in spite of various recommendations that whole plot harvest has been regarded as the most accurate method for measuring crop outputs. It is, however, more feasible on demonstration plots and less so on farmers' plots, especially in cases of large scale surveys (Sapkota et al. 2016) due to time and cost constraints. Additionally, crops with definite maturity dates such as cereals are easier to harvest in a whole plot harvest operation compared to those with indeterminate growth habits such as beans and cassava (Fermont and Benson 2011). Similarly, staggered planting, another common practice among smallholders in SSA can also complicate whole plot harvesting by researchers. The above notwithstanding, this method is ideal for capturing most complete output for plots given that it includes postharvest losses which could be excluded in farmerreported outputs. Thus, this method offers the least level of bias and error for deriving crop outputs from plots.

\section{Crop area estimation}

While crop output forms the numerator of the yield measurement formula, plot area is the denominator. The two most widely used measures of plot area are farmer estimations and GPS area measurement. Several studies have recently reported the substantial inaccuracies that result from reliance on farmers' selfreported area estimations leading to the questioning of the theory on the inverse relationship between plot size and productivity (Carletto et al. 2015; Carletto et al. 2013; Desiere and Jolliffe 2018). Varying sources of the inaccuracies, as enumerated by De Groote and Traoré (2005) include deliberate misreporting due to fear of taxes or belief that they stand to gain certain benefits depending on farm sizes, as well as unintentional misreporting due to limited education and quantitative skills, rounding off based on unit of measurement or variations in measuring units from one village or farmer to the other. A review by Fermont and Benson (2011) found that the reliability of farmer estimates of crop area varies between countries with SSA farmer estimates being most inaccurate. More importantly, the inaccuracy is further affected by crop type and plot size with a tendency to overestimate smaller plots and underestimate larger ones (Carletto et al. 2013). De Groote and Traoré (2005), for instance, found that farmers overestimate plots less than 1 hectare, with farmers able to provide more accurate estimates of cash crop plot sizes than for those of food crops including cereals.

In light of these shortcomings, the GPS method of area measurement, just as is the case with crop cuts, is often regarded as the gold standard given that it drives more objective outcomes. The advantages of the GPS method of area measurement including rapidity, timeefficiency, and ease of application is however counterbalanced by its shortcomings relating to regions with significant cloud cover, large trees on plots and hills with plots on slopes (FAO 2017b). While these shortcomings can be overlooked on larger plots, the errors resulting from GPS area measurement on small plots-less than 0.5 ha-could be substantial (Fermont and Benson 2011). This notwithstanding, GPS area measurement is regarded as best-among-the-rest and hold the potential to significantly improve the accuracy of agricultural data in the context of household surveys (Carletto et al. 2013).

\section{Planted area versus productive area}

Beyond these difficulties associated with crop output and area measurement which is most dire in the SSA agriculture context, other factors further complicate the collection of accurate agricultural yield data in the region. These factors include the presence of intercrops, staggered planting and general heterogeneity in crop performance even within the same plots. These often lead to a situation where the planted area is not congruent with the productive and hence harvested area. Loss of crop area could be the result of poor germination, damage from pests and diseases, animal grazing or extreme weather, as well as floods and erosion activities, crop theft, and abandonment due to unusual economic conditions (Craig and Atkinson 2013; Fermont and Benson 2011). While the disparity between planted and harvested area further complicate yield measurement (Sapkota et al. 2016), many studies fail to specify whether they define crop area as planted area or harvested area and this could significantly impact yield levels. Using plot-level data from Tanzania's National Panel Survey, Reynolds et al. (2015) found that though it may be infrequent on trial plots, area losses are substantial on smallholder plots; with 
$23 \%$ of the sample plots showing harvested area smaller than planted area. They posit that smallholder farmers are far more likely to experience area losses because they are more likely to intensively cultivate marginal plots without adequate replacement of soil nutrients.

While the ideal crop area measure ought to be harvested area rather than planted area, current measurement methods do not adequately capture the latter. The pertinent question then is which of the area measures are reported in national surveys whose data feed into global databases? What are the implications on the narratives on smallholder productivity if the harvested area is used to compute yields? Depending on current traditional methods, however, it may become necessary to make area estimates multiple times in the course of the season in order to capture area loss and harvested area (Craig and Atkinson 2013). While some countries prefer one set of yield measures to others, the United States Department of Agriculture adopts a combination of methods to derive crop yields. Integrating different measures could potentially improve the accuracy of yield estimations.

Complementing traditional methods with remote sensing approaches

The application of remote sensing methods to assess crop status and yields has a long history. However, limitations with regards to the spatial resolution of satellite data imply that it is of limited value at the plot level, particularly in the context of SSA where plots are usually small in size and often intercropped (Fermont and Benson 2011; Gourlay et al. 2017). Notwithstanding this limitation, Zhao et al. (2007) predict that remote sensing will in the future be a keystone of agricultural statistics is not without basis, given recent advances on this front (Craig and Atkinson 2013). At the plot level, several studies (Lobell et al. 2015; Sibley et al. 2014; Singh 2003) have consistently documented moderate to strong correlations between vegetation indices derived from satellite imagery and crop yields. In spite of the promising prospects of these studies even at the plot level, most of the applications have been undertaken on large scale plots. More recently, however, Burke and Lobell (2017) and Lobell et al. (2018) in Kenya and Uganda, respectively, have surmounted the aforementioned difficulties by using higher resolution satellite data to arrive at decent relationships between vegetation indices from smallholder plots and yields. There are still challenges to contend with though because Lobell et al. (2018) found that satellite-based yield estimates were less well correlated with groundbased measures on intercropped plots compared to pure stand ones. Apart from yield estimations, plot area can also be accurately derived using satellite imagery in a geographic information system software. This approach can help enhance the precision of area estimates based on surveys though such a system will need to be regularly updated to the latest area extent (FAO 2017b).

The use of unmanned aerial vehicles (UAVs) however, opens hitherto unconsidered possibilities. Already, Wahab et al. (2018) have demonstrated that similar results as obtained using satellite data are attainable using UAVs on smallholder farms in SSA. On this basis, intra-plot heterogeneity analysis can be undertaken to explore the implications of complementing survey- and field-based measures of yield estimation with UAV data for yield estimation in such farming systems.

\section{Data and methodology}

Study sites and plots sampling

This paper relies on a cross-sectional dataset on two predominantly maize farming communities: Asitey and Akatawia, in the Eastern Region of Ghana (Fig. 1). Of the ten regions in Ghana, the Eastern Region is the second highest producer of maize after Brong Ahafo region. This dataset was collected under the aegis of the Yield Gaps project, a multi-disciplinary study which aims at integrating biophysical and socioeconomic explanations for the significant differences between potential and observed crop yields in Ghana and Kenya. Data was collected during the major farming season which spans the period of April to August 2016. Asitey is located in the relatively more urbanized Lower Manya Krobo Municipality while Akatawia is located in the more rural Upper Manya Krobo District (Fig. 1). Thus, while the two communities are similar in cropping systems and climatic conditions, they differ in important respects such as rurality and urbanity and thus some important socioeconomic characteristics. 


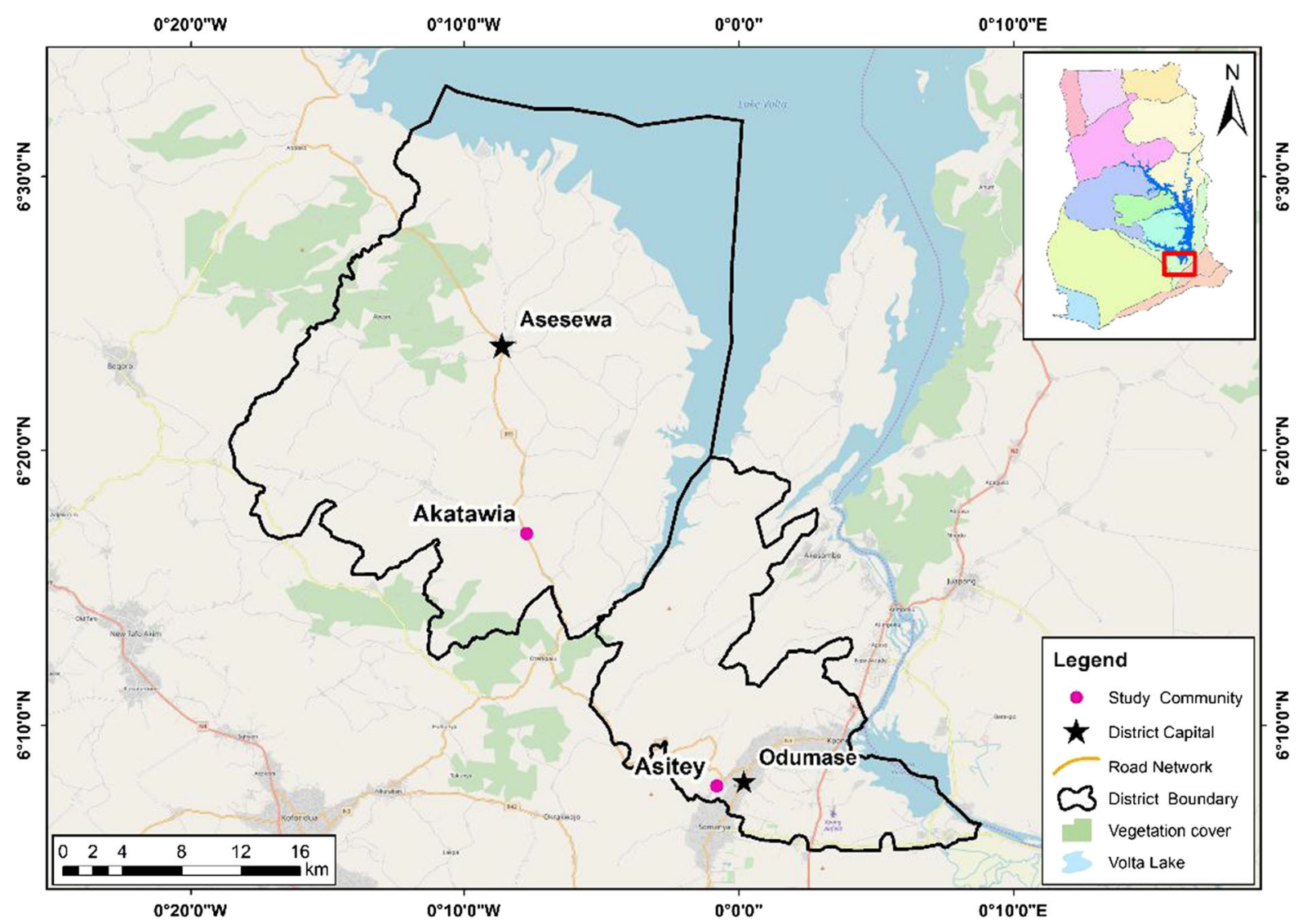

Fig. 1 Map of the study area showing the locations of Asitey and Akatawia and their respective districts

The study uses a multilevel sampling approach. Below the country level, while the region, district, and communities were purposively selected, farming households were sampled using a simple random approach. The sample frame for the present study: 62 and 68 farming households for Asitey and Akatawia, respectively, is the sample for the Afrint study described in detail by Djurfeldt et al. (2011). However, given that this earlier project has been in operation since 2002 and the latest round was conducted in 2012, there was bound to be dropouts. These were replaced with descendants from the same households. Using the frame of 62 and 68 and in a simple random approach, the present study reduced the sample to 30 and 32 farming households for Asitey and Akatawia given the more detailed, multi-disciplinary scope of the data to be collected vis-à-vis the length of the maize growing season. The unit of analysis is, however, maize plots. The approach of sampling maize plots has been detailed by Wahab et al. (2018). In total, 42 and 44 maize plots ${ }^{3}$ for Asitey and Akatawia, respectively are used for the following analyses.

Crop output and area measurement

Here, the methods of maize crop output and area measurement are summarily explained. With regards to output, the two methods used are farmer selfreported (SR) outputs and those based on crop cuts (CC) are detailed while area measurement using a Garmin 64S GPS device as well as plot area derived from georeferenced UAV imagery in an ArcMap environment are detailed below.

\footnotetext{
3 Plot, as used here, is distinct from a whole farm in the sense that a plot is a subset of the farm. A farm may be made up of multiple plots on which different crops are cultivated. The selected maize plot is that which a household considers its main maize plot. This could further be divided where significant heterogeneity is discerned. Some households also had multiple maize plots at different locations.
} 


\section{Farmer self-reported outputs}

Data on crop outputs estimations at the plot level were collected through household surveys conducted 2 months after harvest. Farmers and plot operators were asked to report maize quantity and units harvested from individual maize plots. They were also to report on the condition of dry crops; whether shelled grains or cobs-husked or dehusked. Even harvests in grains had to be probed for the state of the grains in terms of the moisture content as well as the specific size of the bag or bowl used. ${ }^{4}$ Farmers were also asked to report any green maize harvests from the larger maize plot but were implored not to harvest green maize from $\mathrm{CC}$ subplots.

\section{Output based on crop cuts}

The subplots from which CC outputs were measured were demarcated earlier in the season prior to planting. This was done to eschew the possibility of sampling relatively more vigorous sections of plots. The subplots, $4 \mathrm{~m}$ by $4 \mathrm{~m}$ in size, were located at roughly the centre of each maize plot unless this centre coincides with footpaths, former anthills or large trees and these were not widespread in the larger plot. In such a situation, the location of the subplot is moved a few meters from such irregularities to sections which are more representative of the larger plot. While these $16 \mathrm{~m}^{2}$ subplots were, to all intents and purposes, normal parts of the larger plot, farmers were entreated not to harvest maize crops from subplots which had been demarcated with pegs and farmers were well aware of their existence and location. Crops were allowed to dry in fields before harvest, threshing by field enumerators and the grains weighed using a hand scale and the moisture content of each crop cut sample was noted for subsequent standardization at $13 \%$ moisture content.

\footnotetext{
$\overline{4}$ Measurement at the local level is usually in non-standard units such as bowls, locally termed 'olonka', head pans, sack loads, and cobs for green harvests. These data were all collected and converted using a standardized units in kilogrammes. Further probing brings to light, quantities that were used as payment in kind to farm labourers, landowners and plot managers. This is usually not reported for surveys in which farmers are made to estimate and report on their outputs.
}

Global position system area measurement

The crop area measurement was undertaken using a Garmin GPSMAP 64S handheld navigation device (accuracy: $\sim 3 \mathrm{~m}$ ) at the start of the farming season. Each plot operator was made to show by walking the boundary of their respective plots. The enumerators then traversed the perimeter of each plot to measure the area in square meters and the result recorded in an electronic survey form with the raw GPS track stored on the device and later uploaded onto a geodatabase linked to individual plots. Both CC and farmers' SR yields were then computed based on GPS area measurement. ${ }^{5}$ On a couple of plots, areas that were actually cultivated went beyond the area farmers originally planned to cultivate and this became obvious by comparing the shapefiles of plots stored in the geodatabase based on GPS tracks of the area to plot area extracted from georeferenced UAV imagery.

\section{Remote sensing area measurement}

The UAV system deployed in this study is Agribotix's Enduro Quadcopter mounted with two GoPro Hero 4 consumer-grade cameras, one of which had been modified to capture in the near infrared region (NIR). The system is a vertical take-off and land which is flown autonomously at an altitude of $\sim 100$ meters above sea level on the maize plots. Both camera systems independently capture images simultaneously at a shutter speed of $1 \mathrm{~s}$. Post-flight operations including image geotagging, mosaicking and georeferencing were then done using Agribotix's proprietary software packages. A detailed description of the UAV system, as well as image processing protocols, have been explained in Wahab et al. (2018). The NIR mosaics were then imported into ArcMap for additional protocols including projection, clipping individual plot shapefiles, and using the Map Algebra tool to extract the green normalized difference vegetation index by ratioing the NIR reflectance with that of the green band. Thus,

GNDVI $=(\mathrm{NIR}-\mathrm{G}) /(\mathrm{NIR}+\mathrm{G})$,

\footnotetext{
5 Farmer estimations of plot area were ab initio not intended to be collected due to well-catalogued deficiencies with that approach in most SSA countries (Fermont and Benson 2011).
} 
where NIR is reflectance captured in the band 1 of the modified camera, and $\mathrm{G}$ is reflectance captured in the band 2 of the modified camera.

The variances between these two bands enable assessment of crop density and vigour within the plots (Wahab et al. 2018).

A comparison of the plot shapefiles from the GPS area measurement and that georeferenced mosaics showed a discrepancy between the two for 5 of the plots. Further analysis showed that for three of these plots, operators could not carry through their original intentions to plant the whole plots while in two others, they exceeded the area they originally intended to cultivate. This came to light by virtue of comparing the UAV data with reported and GPS-measured area.

\section{Results}

Descriptive statistics

Table 1 summarizes a general description of the farm plots used in the subsequent analysis. This is organized for the overall plot sample for both study locations $(\mathrm{N}=87)$ and then subdivided into the two locations. Comparisons between the two study locations bring up some interesting dynamics in some indicators while in others, there are no significant differences between the two locations. For example, while no significant differences exist between the two communities in terms of the average maize plot sizes, the proportion of maize plots intercropped and even proportion of plots planted with certified seeds, significant differences exist with regards to total household landholding, average land holding under fallow and distances between maize plots and farmers' dwelling.
Additionally, there are significant differences between yields-both SR and CC yields between Asitey and Akatawia. Generally, yields are higher in Akatawia than in Asitey; SR yields in Akatawia is on average $791 \mathrm{~kg} / \mathrm{ha}$ compared to an average of $501 \mathrm{~kg}$ / ha for Asitey. Similarly, CC yields on the average are also higher in Akatawia; $2305 \mathrm{~kg} / \mathrm{ha}$ compared to $2036 \mathrm{~kg} / \mathrm{ha}$ in Asitey. More interesting is the substantial differences between SR and CC yields for the same villages. This discrepancy between CC and SR yields is the subject of the next section.

The disparity between farmer SR and CC yields

A comparison of maize yields based on farmers' SR and the CC approach returns some interesting findings. Table 2 shows a breakdown for the two measures of crop yields for the two study locations.

Overall, average measured CC yields are substantially higher $(2174 \mathrm{~kg} / \mathrm{ha})$ than average SR yields $(651 \mathrm{~kg} / \mathrm{ha})$ (Table 1). However, an interesting dynamic is uncovered when the two communities are compared. From Table 2, while CC yields were higher for both communities than SR yields, the former is much more variable, with a standard deviation of $1053 \mathrm{~kg} / \mathrm{ha}$ for Asitey compared to $644 \mathrm{~kg} / \mathrm{ha}$ for Akatawia. More interestingly, this trend does not repeat for SR yields with a standard deviation of $360 \mathrm{~kg} / \mathrm{ha}$ for Asitey compared to $518 \mathrm{~kg} / \mathrm{ha}$ for Akatawia. The breakdown thus suggests more variability in CC yields compared to farmers' SR yields and that this observed variability in CC yields is more pronounced at Asitey than Akatawia. The reverse, however, holds for farmer's SR yields; $360 \mathrm{~kg} / \mathrm{ha}$ and $518 \mathrm{~kg} / \mathrm{ha}$ for Asitey and Akatawia respectively.

For our dataset, the difference between the two measures of crop yields is substantial, so much so that,
Table 1 Summary statistics of the characteristics of plots and yields in study communities

$\mathrm{N}=87$; unless specified otherwise, values in parenthesis are standard errors of the means

$S R$ self-reported, $C C$ crop cut

\begin{tabular}{llll}
\hline Indicator & Asitey & Akatawia & Both communities \\
\hline Average household landholding size, SR, acres & $8.93(1.09)$ & $13.89(1.45)$ & $11.49(0.95)$ \\
Average household land under fallow, acres & $4.29(1.00)$ & $7.29(1.01)$ & $5.84(0.73)$ \\
Average maize plot size, GPS-measured, acres & $1.02(0.12)$ & $1.04(0.09)$ & $1.03(0.07)$ \\
Proportion of maize plots intercropped & 29 & 31 & 30 \\
Average distance to plot from dwelling, km & $1.25(0.17)$ & $0.64(0.06)$ & $0.93(0.09)$ \\
Proportion of plots planted with certified seeds & 10 & 7 & 8 \\
SR maize yields, (GPS area), kg/ha & $501(56)$ & $791(78)$ & $651(51)$ \\
CC maize yields, (GPS area), kg/ha & $2036(162)$ & $2305(97)$ & $2174(94)$ \\
\hline
\end{tabular}


Table 2 Comparison of the variability of GPS plot areabased crop cut and selfreported maize yields for Asitey and Akatawia

Values in parenthesis are standard errors of the mean

\begin{tabular}{lrrrrr}
\hline Village & N & Minimum & Maximum & Mean & SD \\
\hline Akatawia & & & & & \\
$\quad$ Farmer SR yields (kg/ha) & 44 & 164.93 & 2514.68 & $790.77(78)$ & 518.08 \\
$\quad$ Measured CC yields (kg/ha) & 44 & 924.38 & 4458.75 & $2305.33(97)$ & 643.66 \\
Asitey & & & & & \\
Farmer SR yields (kg/ha) & 42 & 22.47 & 2012.64 & $501.50(56)$ & 359.82 \\
Measured CC yields (kg/ha) & 42 & 437.50 & 5274.38 & $2035.82(162)$ & 1053.06 \\
\hline
\end{tabular}

Fig. 2 Comparison of measured-CC and farmer SR-yields. Substantial differences between SR yields and yields based on the $\mathrm{CC}$ approach

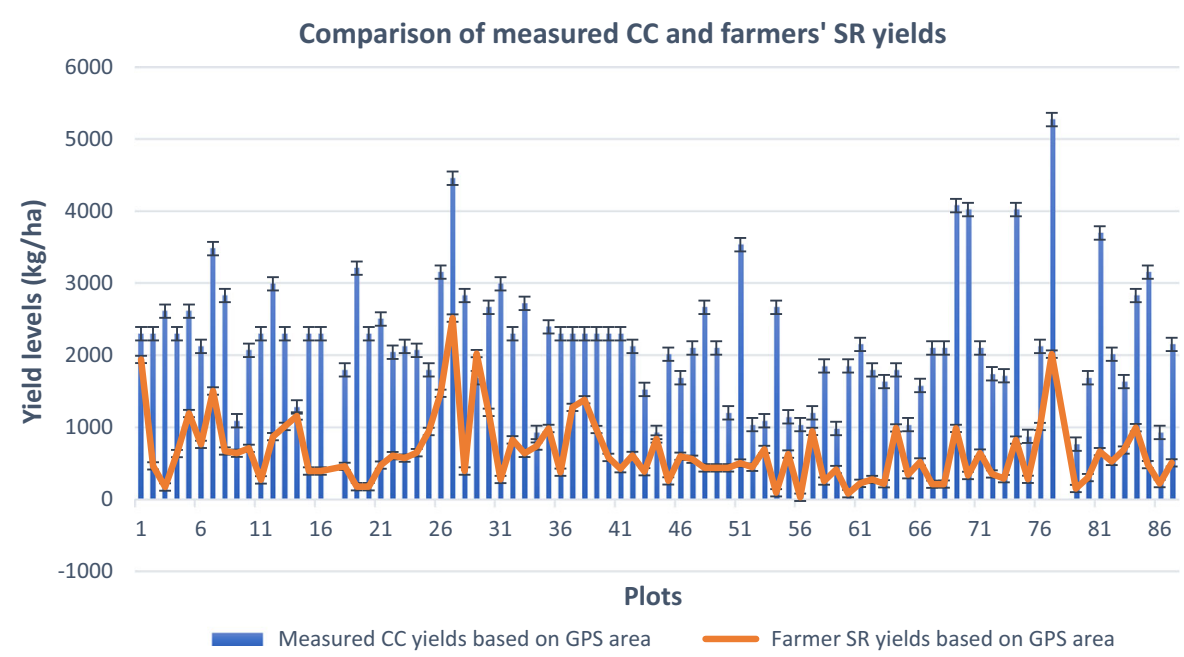

in some plots, CC yields are multiples of farmer SR yields. This difference cannot single-handedly be explained by the generally more thorough harvests of the CC approach. Also, while GPS area may have its limitations (to be explored in the next section), such limitations have been controlled for by using the same variable as the denominator for deriving both $\mathrm{CC}$ and SR yields.

As Fig. 2 shows, farmers' SR yields are significantly lower compared to measured yields based on the CC approach. It is, therefore, our hypothesis that $\mathrm{CC}$ yields rather overestimate plot level maize yields, particularly among plots which display a high level of within-plot heterogeneity. This upward bias of CC yields could thus be attributed, at least partly, to the general central locations of subplots where crop performance is generally better. Generally, when sampling CC subplots, edges, and borders of plots where crop stands are generally poorer are excluded. If these assumptions hold, then a direct positive relationship between plot area and mean deviation in yields (computed as CC yields-SR yields by plot area) is to be expected.

As Fig. 3 shows, no clear trend is discernible for the relationship between the size of the maize plot and how significantly measured CC yields differ from farmers' SR yields. The absence of any significant relationship $\left(\mathrm{R}^{2}=0.07\right)$ suggests that plot size alone does not explain the deviation. It is, therefore, our hypothesis that the $\mathrm{CC}$ approach to yield estimation overestimated yields or that there was under-reporting-deliberately or inadvertently-of crop outputs by farmers. The possible basis for overestimation of yields by the CC approach is the location of the CC subplot which may not be representative of the larger plot area in terms of crop density and vigour.

Intra-plot variability

An inherent underlying assumption of the CC approach to yield estimation is the representativeness of the sampled subplot relative to the larger plot. This assumption may, however not hold in significantly 
Fig. 3 Deviations in yields relative to increasing plot area. No apparent relationship between the degree of deviation between measured CC yields and farmer-SR yields and plot size

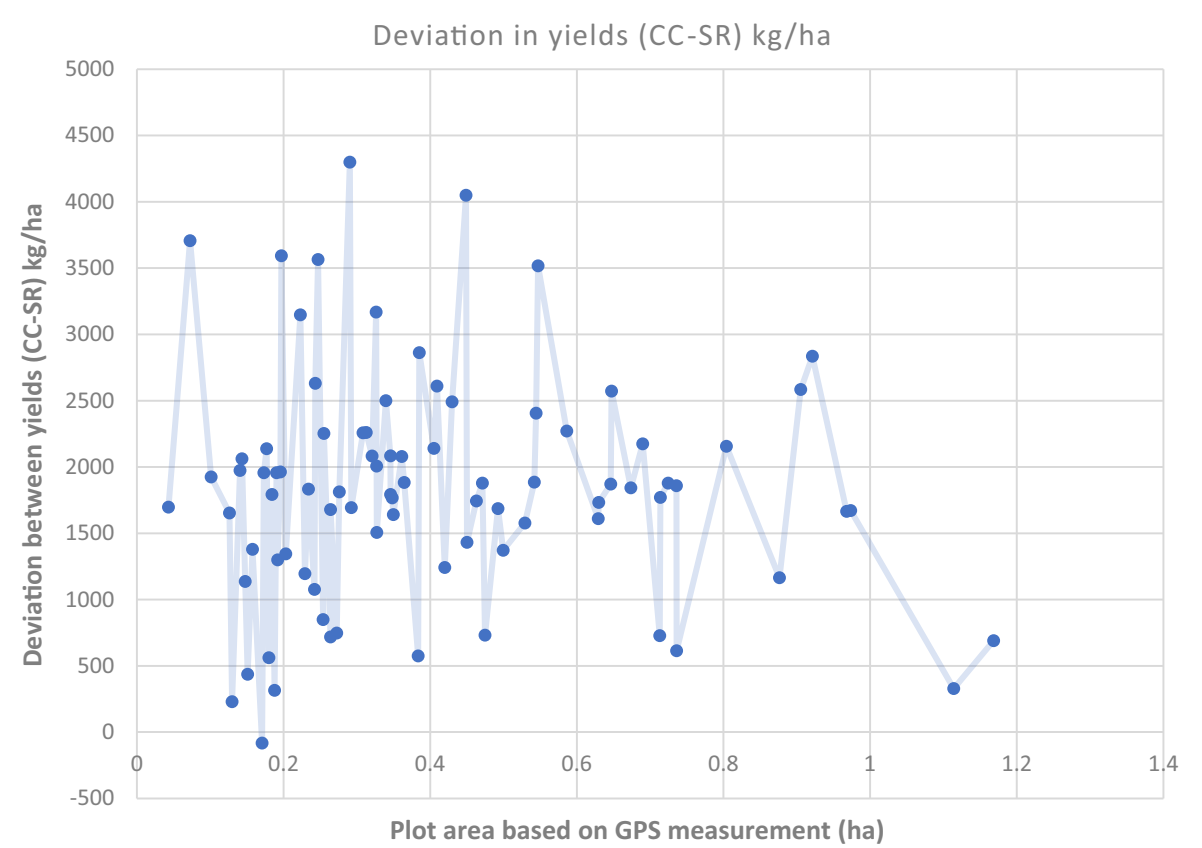

heterogeneous plots. A certain level of heterogeneity is to be expected, even at the plot level. However, in the context of SSA smallholder plots where the limited application of machinery is common, homogeneity in plot-level crop performance is uncommon. From Fig. 4, even for a relatively flattened surface, significant levels of intra-plot heterogeneity in crop vigour is still discernible. Thus, the sampling of $16 \mathrm{~m}^{2}$ subplots at the approximate centre of each plot where crop vigour is above average would most likely lead to overestimation when yields are extrapolated to the whole plot.

From visual inspection of Fig. 4, plot B1 appears to be more homogeneous at the plot level with crops relatively more vigorous over most parts of the plot and so wherever the location of the subplot, the CC approach might not overestimate yields as much as it would in plots A1, A2, and B2 in which crops appear sparser with significant heterogeneity. Thus, general crop vigour might contribute significantly to $\mathrm{CC}$ yield overestimation. It is pertinent to note that the level of heterogeneity might be even higher in the overall sample given that a significant proportion of plots are not ploughed as these four plots shown in Fig. 4 were. From the overall sample, the majority of the plots (70\%) had poor patches of crop vigour close to the edges of the plots, especially when these plots share boundaries with uncultivated parcels of land. A few had poor patches in and around the centre of the plots. The crop health maps also show some poor patches following ploughing lines. The observed intra-plot heterogeneity could, therefore, lead to significant differences between the two yield measures where the number and size of the sampled subplot do not representatively capture the heterogeneity of the whole plot. However, this heterogeneity alone cannot explain the observed discrepancy. Given that both yield measures were based on the GPS plot area, there was the need to validate it by comparing it to area derived from the remotely-sensed UAV images.

Comparison of GPS- and RS-plot area measurement

There are strong associations $\left(\mathrm{R}^{2}=0.80\right)$ between GPS-measured plot area and RS-measured plot area. The minor differences in a few observations are attributable to changes in the extent of intended cultivation area by farmers in the course of the farming season. ${ }^{6}$ The mirroring of the two measures of area persists irrespective of plot sizes. That is, deviations

\footnotetext{
$\overline{6}$ This affected only 5 plots from both communities. Of this, 2 plots were exceeded with regards to the extent of originally intended plot area while for the remaining 3, farmers could not carry through the full extent of intended cultivation area.
} 


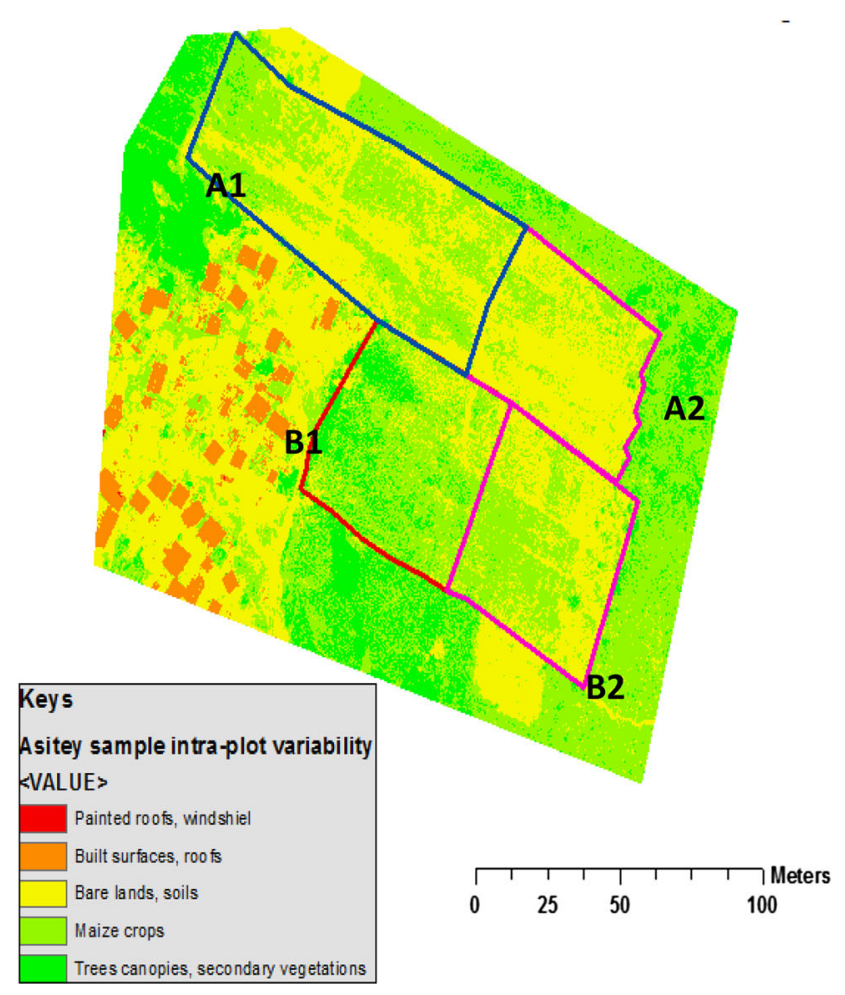

Fig. 4 Intra-plot maize crop vigour variability in four plots at Asitey after approximately 9 weeks after planting. These plots, unlike most others in this study area, were ploughed with a

between the two measures are not affected by plot size. The similarity between the two measures of plot area is obvious from Table 3 .

When the plot area is disaggregated to the village level, however, slight differences emerge. While the difference between GPS- and RS-measured plot areas is largely insignificant overall, there are some subtle differences at the village level (Table 4).

From Table 4, while mean plot sizes are similar for both area measures in both study locations; 1.04 $(\mathrm{SD}=0.58)$ and $1.13(\mathrm{SD}=0.59)$ for GPS- and RSmeasured plot area respectively for Akatawia, those for Asitey were $0.96(\mathrm{SD}=0.57)$ and $0.92(\mathrm{SD}=$ 0.62 ) for GPS- and RS-measured plot area respectively. More interestingly, total GPS- and RS-based plot area does not differ significantly-less than an acre-in Akatawia compared to Asitey where the difference is more than 4 acres (Table 4).

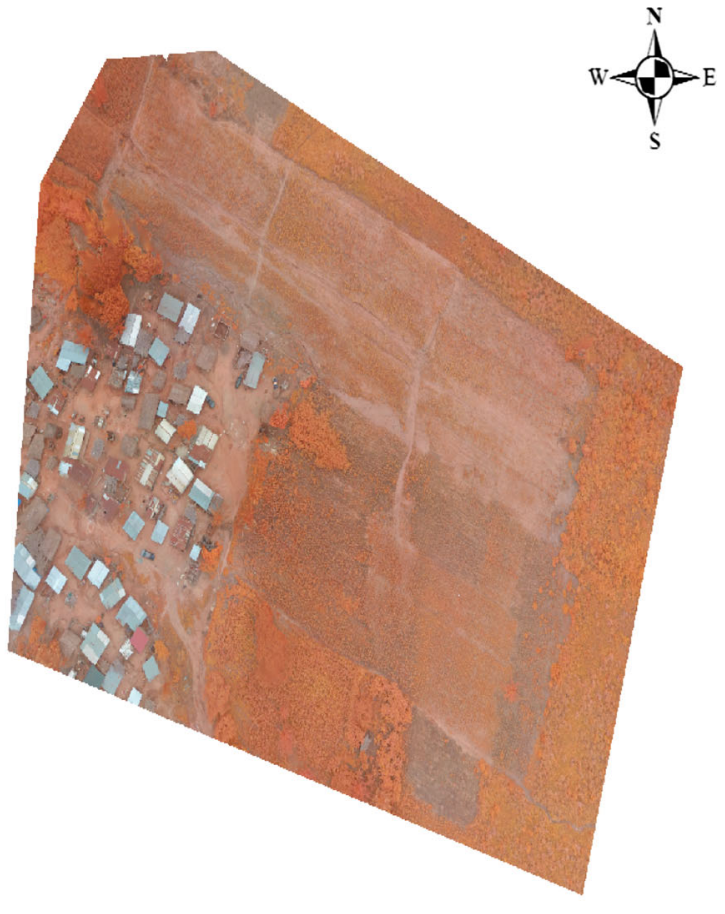

tractor prior to planting of maize and so a certain level of homogeneity in crop vigour ought to be expected

In-season cropped area loss

To evaluate the effect that within-field heterogeneity could have on current measures of crop yield, we set out to assess the proportion of each plot area which turned out to be unproductive in the course of the season in spite of having been planted. That is, the unproductive plot area is conceptualized as the area of each plot which ought to have maize crops but does not have any halfway through the growing season. The unproductive plot was subtracted from the whole plot area to arrive at the productive plot area for each maize plot. Thus, the productive plot area is equivalent to the total plot area minus the cropped area lost. From our sampled plots, a significant proportion-82\%-lost more than $10 \%$ of the plot area. This is significant given that plot area is one of two variables-the denominator-for computing crop yields levels. Overall, about 8 acres $(23 \%)$ of the planted plot area was lost in the course of the season in both locations 
Table 3 Comparison between GPS- and RS-measured plot area

\begin{tabular}{|c|c|c|c|c|c|c|}
\hline Area measure & $\mathrm{N}$ & Minimum & Maximum & Sum & Mean & $\mathrm{SD}$ \\
\hline GPS-measured plot area (acres) & 83 & 0.1293 & 2.6911 & 82.78 & 1.00 & 0.57 \\
\hline RS-measured plot area (acres) & 83 & 0.1061 & 2.8872 & 81.14 & 1.03 & 0.61 \\
\hline
\end{tabular}

This takes into account the area of plots for which both measures are available. Also, plots whose original extents have not been altered by farmers either by not cultivating the full extent or cultivating beyond the initially-intended area have been excluded

Table 4 Village level comparison of GPS- with RS-measured plot area

\begin{tabular}{lllllll}
\hline GPS- and RS-measured plot area & & & & & & \\
\hline Village & $\mathrm{N}$ & Minimum & Maximum & Sum & Mean & SD \\
\hline Akatawia & & & & & & \\
GPS-measured plot area (acres) & 44 & .27 & 2.69 & 45.70 & 1.04 & .58 \\
RS-measured plot area (acres) & 44 & .25 & 2.41 & 45.15 & 1.13 & .59 \\
Asitey & & & & & & \\
GPS-measured plot area (acres) & 39 & .13 & 2.36 & 39.26 & .96 & .57 \\
RS-measured plot area (acres) & 39 & .11 & 2.89 & 34.98 & .92 & .62 \\
\hline
\end{tabular}

Fig. 5 Comparison of the productive area of plots relative to the GPS- and RSmeasured plot area

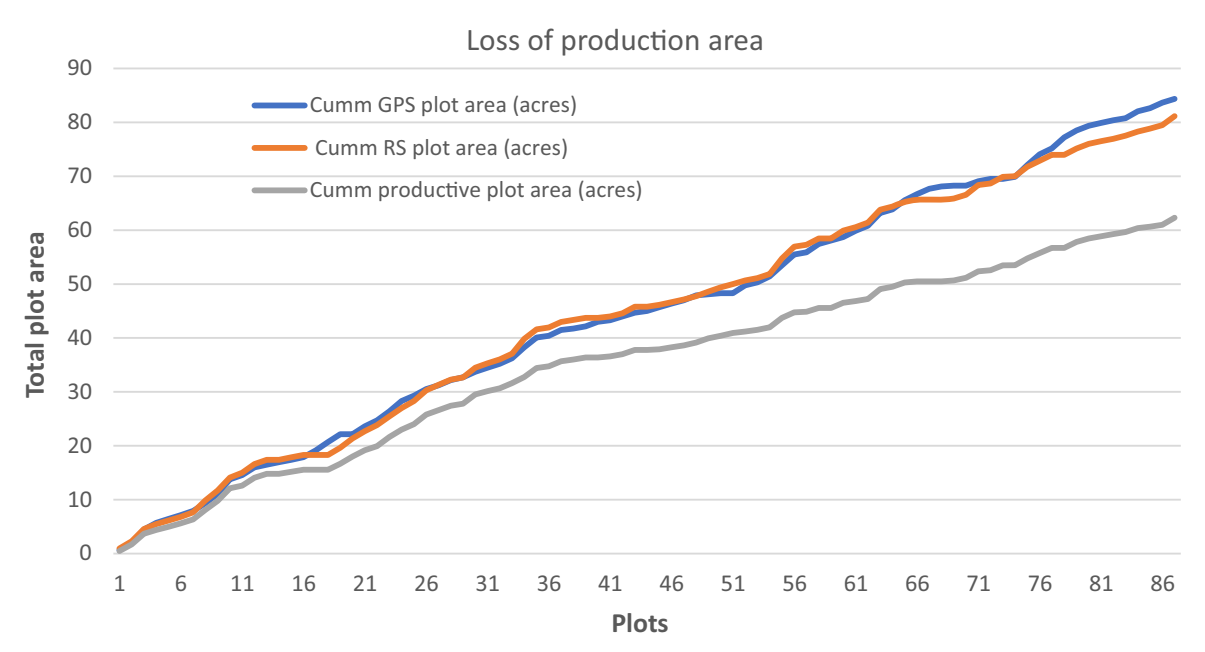

(Fig. 5). This has important implications for yield computation.

Again, more interesting findings result when the plot area loss is disaggregated to the village level. As Table 5 shows, planted area loss is more severe in Asitey than in Akatawia. Thus, at the village level, while about 8 acres $(18 \%)$ of the planted area was lost in Akatawia, almost 11 acres (30\%) of the planted area became unproductive in Asitey in the course of the season (Table 5).

This is validated by a sample of the GNDVI results from the UAV images for both communities as shown in Fig. 6. What is obvious from Fig. 6 is the importance of the so-called edge and border effects and their association with poor patches even for a relatively vigorous plot like Plot $\mathrm{D}$. The border effect is, however, worse in relatively poorer plots. Other poor patches could be the result of management practices. These losses in crop area would have significant implications for how farm productivity is calculated.

It is pertinent to note however that, the intra-plot crop vigour heterogeneity as shown in Figs. 4 and 6 cannot adequately explain the substantial disparity between measured CC yields and farmers' SR yields. 
Table 5 Community-level plot area loss analysis

\begin{tabular}{|c|c|c|c|c|c|c|}
\hline Village & $\mathrm{N}$ & Minimum & Maximum & Sum & Mean & SD \\
\hline \multicolumn{7}{|l|}{ Akatawia } \\
\hline GPS-measured plot area (acres) & 40 & .27 & 2.69 & 45.70 & 1.04 & .58 \\
\hline RS-measured plot area (acres) & 40 & .25 & 2.41 & 45.15 & 1.13 & .59 \\
\hline Productive plot area (acres) & 40 & .10 & 2.33 & 38.13 & .95 & .56 \\
\hline \multicolumn{7}{|l|}{ Asitey } \\
\hline GPS-measured plot area (acres) & 39 & .13 & 2.36 & 39.26 & .96 & .57 \\
\hline RS-measured plot area (acres) & 39 & .11 & 2.89 & 34.98 & .92 & .62 \\
\hline Productive plot area (acres) & 39 & .05 & 1.85 & 24.42 & .64 & .43 \\
\hline
\end{tabular}

Productive area is computed as the total plot area (RS-measured) minus the unproductive portions of each plot. Asitey suffered relatively more plot area compared to Akatawia though the phenomenon cropped area loss was present in both study villages
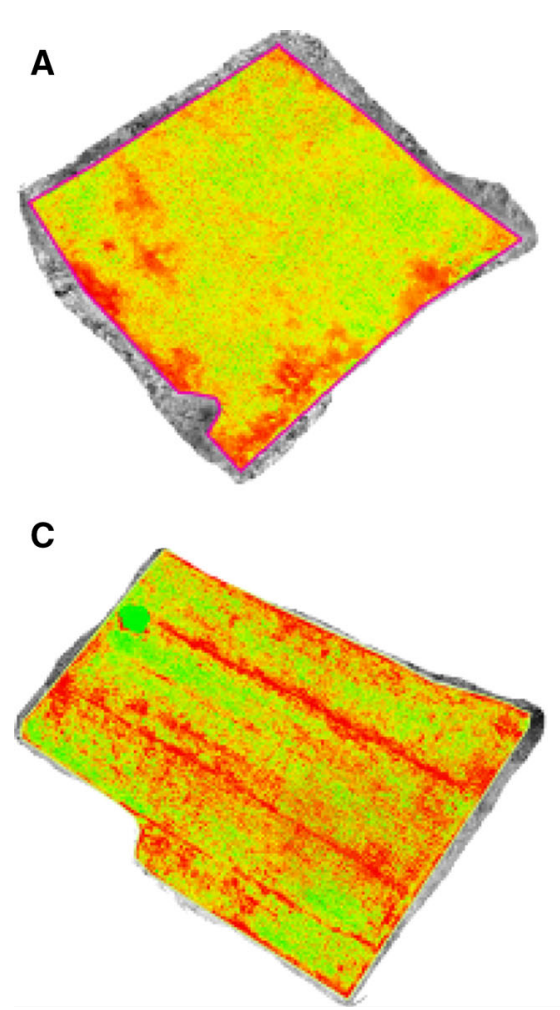

Fig. 6 Loss of crop area in the course of the season on a sample of plots from both study communities. Plot in c at Asitey experienced substantial cropped area loss though plots

That is, while the CC approach to yield estimation has the inherent tendency to overestimate yields due to the location of the CC subplot vis-à-vis edge effects on crop vigour, it cannot adequately account for the difference. To discount the role of the unproductive segments of plots on yield estimation, both yield

B

D
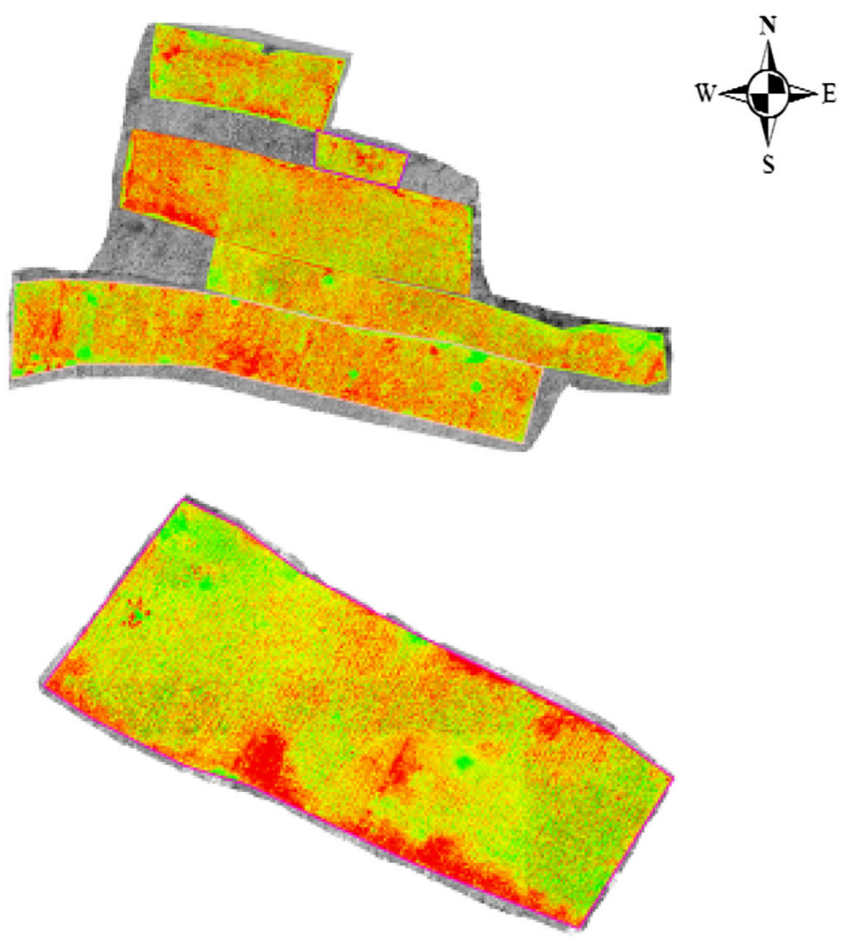

a (Asitey) and d (Akatawia) also lost significant areas, especially around the edges compared to those in $\mathbf{b}$ also in Akatawia

measures are recalculated based on the productive plot area rather than the planted plot area.

As Table 6 shows, when the unproductive segments of plots are not factored in, yields improve substantially. For example, farmers SR yields increase from 679 and $734 \mathrm{~kg} / \mathrm{ha}$ to 1066 and $923 \mathrm{~kg} / \mathrm{ha}$ for 
Table 6 Comparison of yield measured based on productive plot areas for both Asitey and Akatawia

\begin{tabular}{llc}
\hline Community & Yield measure & Yield level (kg/ha) \\
\hline Asitey & Farmer SR yields (based on GPS plot area) & 502 \\
& Farmer SR yields (based on RS plot area) & 679 \\
& Measured CC yields (based on GPS plot area) & 2035 \\
& Measured CC yields (based on productive area) & 2362 \\
& Farmer SR yields (based on productive plot area) & 1066 \\
Akatawia & Farmer SR yields (based on GPS plot area) & 791 \\
& Farmer SR yields (based on RS plot area) & 734 \\
& Measured CC yields (based on GPS plot area) & 2306 \\
& Measured CC yields (based on productive area) & 2676 \\
& Farmer SR yields (based on productive plot area) & 923 \\
\hline
\end{tabular}

Asitey and Akatawia, respectively. Similarly, measured CC yields increase from 2035 and $2306 \mathrm{~kg} / \mathrm{ha}$ to 2362 and $2676 \mathrm{~kg} / \mathrm{ha}$ for Asitey and Akatawia, respectively. Thus, depending on the definition of plot area-whether GPS area, RS area or even productive area-yield values differ.

\section{Discussions}

In this section, key findings and their implications are discussed. While there are limitations with regards to the sample size of the plots, the findings are representative at the village level given that the plots were sampled from households that are representative of all maize farming households of each village. Both study villages have agriculture as the most important economic activity, engaged in by a large proportion of the households. In spite of the centrality of agriculture and its productivity on the welfare and poverty reduction and food security, particularly for rural households in the context of SSA, there are still no clearly reliable and validated methods for accurately estimating crop yields. Methods that are viewed as more objective still come with a number of limitations which in turn have important implications on yield measurement. Thus, attempts to average yields over large areas; landscapes to entire regions and countries, are likely to be rife with challenges.

Yield variability between and within study communities

The findings show that using both yield measurement approaches produces different results even for the same dataset for the same location. Overall, our findings show that farmer SR yields are lower than CC yields for both locations together. This is in stark contrast to findings of other studies by Gourlay et al. (2017) and Lobell et al. (2018) in Uganda which found that average farmer SR yields are more than double $\mathrm{CC}$ yields. The major difference between the approaches used in those studies and the present one is that they used multiple CC subplots (4-5 subplots per farm plot) even though the subplots were smaller in some cases relative to the present study. However, similar to our findings, Sapkota et al. (2016) find that CC yields consistently exceed SR yields due to an inherent bias when extrapolating results to a larger area. Thus, devoid of any sampling and non-sampling errors, CC yields would normally be higher than farmer SR yields (Fermont and Benson 2011). Farmer SR yields have been noted to be inexact in estimating yields. There is a tendency to omit from their reports on crop outputs quantities that have been used as payment for land rental, especially when sharing of the output is done at the point of harvest. Other sources of error include deliberate and unwitting over- or underestimation and errors resulting from reporting outputs in non-standard units. Farmers may also underestimate their production if they perceive that some form of benefits would be due them if their plots are not performing well (Gourlay et al. 2017). This could have played an important role in the low yields obtained using farmers' SR outputs. These notwithstanding, and in spite of the endorsement of the CC approach, SR remains the most popular method for estimating yields in most SSA countries including Ghana.

In spite of it being touted as the gold standard, the $\mathrm{CC}$ approach is not without its limitations. While these 
limitations may not have serious implications for largely uniform plots, they can have important ramifications for the validity of computed yields for plots with a significant level of heterogeneity. A way around this limitation in the context of heterogeneous plots is thus to sample several subplots within each plot as was done by (Gourlay et al. 2017) as well as increase the sizes of the CC subplots. This, however, has implications for costs and may therefore not be practical when the study involves a large sample or on a limited budget. Using CC yields as reference yields however, there is a significant level of yield variability and this variability is more acute in Asitey compared to Akatawia as shown by the higher variance in Table 2 .

To provide context for our findings, Upper Manya Krobo where Akatawia is located had an average maize yield of $1920 \mathrm{~kg} / \mathrm{ha}$ over a 3-year period, compared to $2280 \mathrm{~kg} / \mathrm{ha}$ for Lower Manya Krobo where Asitey is located (MoFA-SRID 2017). Thus, our findings with regards to average SR and CC yields of $651 \mathrm{~kg} / \mathrm{ha}$ and $2174 \mathrm{~kg} / \mathrm{ha}$, respectively, throw up some important debates particularly with regards to the SR yields. It is noteworthy, however, that CC yields are comparable to secondary yield data from these locations. It is also pertinent to point out that the particular farming season during which data were collected for the present study was an unusually poor one. It was during this season that the Fall Armyworm (Spodoptera frugiperda) devastated large plots of maize farms in the country. Thus, while the extremely low SR yields could be partly ascribed to underreporting by farmers, it is important to reiterate that yields were generally poor for that particular season. As our analyses show, however, such district level comparisons can gloss over some important variabilities at the plot and community level. Thus, while average $\mathrm{CC}$ yields are comparable to the national average, there is a significant proportion of plots which are yielding much lower than the national average. This is important because of the linkage between plot level productivity and household food security.

Intra-plot crop performance variability and inseason area loss

Apart from the high yield variability at the plot level, our analyses also show that CC yields tended to overestimate yields by virtue of the significant intraplot crop performance. This calls into question the applicability of the CC approach to yield estimation particularly in the context of smallholder farms in SSA which are characterized by significant intra-plot variability. Relative to the two communities, Asitey appears to have a higher level of intra-plot crop performance variability than Akatawia. This heterogeneity feeds into higher yield variability in Asitey relative to Akatawia. Analysing yields at the plot and community levels is more useful because this brings to the fore certain nuances that tend to be glossed over when analyses are done at the district, regional and national levels. For instance at the district level, according to the latest statistics from Ghana's Ministry of Food and Agriculture (MoFA-SRID 2017), Lower Manya Krobo is said to be performing better in terms of maize yields relative to Upper Manya Krobo district. However, at the village level within our dataset, maize yields for Asitey are lower than Akatawia for both yield measures. This is validated by the use of RS approaches. This is not to claim that our selected villages are representative of their respective districts. It, however, demonstrates the need to integrate methods in order to comprehensively capture agricultural performance at micro scales.

While the CC approach might more accurately capture plot productivity in relatively homogeneous farming systems in more developed agricultural settings, it comes with significant limitations in the SSA context with significant intra-plot heterogeneity. Context, therefore, matters for the appropriateness of the choice of yield measurement methods. This is exemplified by the differences between the two methods of plot area measurement tested in this study. While the difference between GPS- and RS-measured plot areas is insignificant for Akatawia-about 1\%the GPS overestimates plot area relative to the RS approach by up to $7 \%$ in Asitey. This finding is expected given that the GPS device has been shown to have reduced accuracy under certain plot conditions such as where the plot is very small in size, located on steeper slopes, and has significant tree cover (FAO 2017b; Fermont and Benson 2011). With regards to our study communities, Asitey more aptly fits this description. For instance, $79 \%$ of the plots in Asitey are located on terrains with slopes of above $4 \%$ compared to only $23 \%$ of plots in Akatawia fitting this criterion. Similarly, there is more tree cover on Asitey plots than on Akatawia plots. For instance, $22 \%$ of the plots in Asitey are being used by farmers in caretaker 
roles with the parcels being controlled by the Forestry Commission and thus as part of the conditions for continued use of the plots, farmers are duty-bound to nurture teak trees on the same plots that they cultivate maize crops. No such arrangement exists in Akatawia. It is therefore conceivable that Asitey plots would have denser tree canopies compared to Akatawia and thus limit the accuracy of GPS devices. Thus, while GPS area measurement is still regarded as the best-inclass and most objective method for plot area measurement, the reduced accuracy of the GPS device under stated circumstances implies that its accuracy could be impaired. A comparison of the GPSmeasured plot area with RS-measured plot area from UAV imagery is therefore important given that the accuracy of the latter is not influenced by the relative plot size and tree cover.

Implications of using productive area instead of planted area

The higher heterogeneity in Asitey plots can also be inferred from the relatively higher proportion of planted area loss in Asitey compared to Akatawia. Heterogeneity leads to the situation where significant proportions of plot area become unproductive in the course of the season. This is noteworthy because most studies often do not provide a working definition of plot area and this could range from the planted area, productive area or even harvested area. As Craig and Atkinson (2013) point out, plot area may change throughout the growing season as a result of extreme weather damage, abandonment, or unusual economic conditions and thus, to be able to accurately derive plot area, it is often necessary to make area estimates multiple times throughout the season. Integrating RS methods not only renders multiple area measurements unnecessary but also, it is able to accurately demarcate productive and unproductive segments of plots. Persisting with yield estimation based on planted area assumes uniform treatment of whole plot by farmers including the unproductive sections resource allocation. On the one hand, if farmers continue to dissipate resources such as fertilizers on poor patches especially the edges of plots shown in Fig. 5, then yield estimation ought to use the whole plot area. On the other hand, if farmers amend their activities on plots relative to the productiveness or otherwise of plots, then an accurate estimation of plot productivity ought to account for this. Given the economic rationality of farmers, it ought to be expected that they would not dissipate already scarce resources on unproductive sections of plots.

It is our contention therefore that it is more reasonable to base yield estimations on the productive area which has been shown to be significantly different from the planted area in our dataset. Using productive rather than planted area would mean that CC yields in Asitey are, on average $2362 \mathrm{~kg} / \mathrm{ha}$ relative to $2676 \mathrm{~kg}$ / ha in Akatawia. More interestingly, farmers' SR yields increase from 502 to $1066 \mathrm{~kg} / \mathrm{ha}$ and from 791 to $923 \mathrm{~kg} / \mathrm{ha}$ for Asitey and Akatawia, respectively. This has important implications for yield measures. It is pertinent to note, however, that estimating yields based on productive area, and thus, discounting plot area lost in the course of the farming season, ignores the detrimental role that of the factors which lead to the existence of such poor patches (Reynolds et al. 2015).

\section{Conclusions}

From the foregoing, it is obvious that the validity of yield measurement variables is, at least to a certain degree, context-specific. Thus, while they may be accurate in certain crop production settings, they may be inadequate in capturing agricultural dynamism and productivity in others. Even the so-called gold standards of yield measurement have weaknesses that have important implications for yield levels, particularly for heterogeneous farming systems such as those in SSA. Not only does the crop cutting approach overestimate yields partly due to unproductive patches especially around the edges of plots in this context but also, GPS-measured plot area has inherent inaccuracies depending on plot sizes, location on slopes as well as the degree of tree cover. Thus, while crop yields may vary significantly even within settings with the same growing conditions, methods of measuring yield levels could potentially have important implications for captured yields on the same plots. The multiplicity of yield measurement approaches will have to be integrated in order to adequately capture plot productivity at the micro levels. At the very least, RS tools and methods can serve as powerful validation tools in this regard. 
Author contribution The funders had no role in the design of the study; in the collection, analyses, or interpretation of the data; in the writing of the manuscript, or the decision to publish results thereof.

Funding Funding for the study was provided by Swedish Research Council for the Environment, Agricultural Sciences, and Spatial Planning (FORMAS), The Swedish Research Council (VR), and the Crafoord Foundation.

\section{Compliance with ethical standards}

Conflict of interest The author declares they have no conflict of interest.

Human and animal rights No animals were involved in this study. All human participants gave their informed consent to participate in this study. They also had the right to withdraw the consent given and to not answer questions they were uncomfortable doing so. For purposes of protecting the anonymity of participants, the data has been coded in such manner that all identifying characteristics have been removed. The anonymization process, however, does not distort the scientific import and meaning of the original data.

Open Access This article is distributed under the terms of the Creative Commons Attribution 4.0 International License (http:// creativecommons.org/licenses/by/4.0/), which permits unrestricted use, distribution, and reproduction in any medium, provided you give appropriate credit to the original author(s) and the source, provide a link to the Creative Commons license, and indicate if changes were made.

\section{References}

Beddow, J. M., Hurley, T. M., Pardey, P. G., \& Alston, J. M. (2015). Food security: Yield gap. In N. V. Alfen (Ed.), Encyclopedia of agriculture and food systems (Vol. 3, pp. 352-365). San Diego: Elsevier.

Ben-Ari, T., \& Makowski, D. (2014). Decomposing global crop yield variability. Environmental Research Letters, 9(11), 114011. https://doi.org/10.1088/1748-9326/9/11/114011.

Burke, M., \& Lobell, D. B. (2017). Satellite-based assessment of yield variation and its determinants in smallholder African systems. Proceedings of the National Academy of Sciences. https://doi.org/10.1073/pnas.1616919114.

Carletto, C., Jolliffe, D., \& Banerjee, R. (2015). From tragedy to renaissance: Improving agricultural data for better policies. Journal of Development Studies, 51(2), 133-148. https:// doi.org/10.1080/00220388.2014.968140.

Carletto, C., Savastano, S., \& Zezza, A. (2013). Fact or artifact: The impact of measurement errors on the farm size-productivity relationship. Journal of Development Economics, 103(2013), 254-261. https://doi.org/10.1016/j.jdeveco. 2013.03.004.

Craig, M., \& Atkinson, D. (2013). A literature review of crop area estimation. Rome: For the Food and Agriculture Organization of the United Nations.
De Graaff, J., Kessler, A., \& Nibbering, J. W. (2011). Agriculture and food security in selected countries in Sub-Saharan Africa: Diversity in trends and opportunities. Food Security, 2011(3), 195-213.

De Groote, H., \& Traoré, O. (2005). The cost of accuracy in crop area estimation. Agricultural Systems, 84(1), 21-38. https://doi.org/10.1016/j.agsy.2004.06.008.

Desiere, S., \& Jolliffe, D. (2018). Land productivity and plot size: Is measurement error driving the inverse relationship? Journal of Development Economics, 130(2018), 84-98. https://doi.org/10.1016/j.jdeveco.2017.10.002.

Djurfeldt, G., Aryeetey, E., \& Isinika, A. C. E. (2011). African smallholders: Food crops, markets and policy. Oxfordshire: CAB International.

Falconnier, G. N., Descheemaeker, K., Mourik, T. A. V., \& Giller, K. E. (2016). Unravelling the causes of variability in crop yields and treatment responses for better tailoring of options for sustainable intensification in southern Mali. Field Crops Research, 187(2018), 113-126. https://doi. org/10.1016/j.fcr.2015.12.015.

FAO. (2017a). Ending poverty and hunger by investing in agriculture and rural area. Rome: Food and Agriculture Organization of the United Nations. Retrieved from http:// www.fao.org/3/a-i7556e.pdf.

FAO. (2017b). Methodology for estimation of crop area and crop yield under mixed and continuous cropping: Food and Agriculture Organization of the United Nations and Global Strategy for Improving Agricultural and Rural Statistics.

Fermont, A., \& Benson, T. (2011). Estimating yield of food crops grown by smallholder farms: A review of the Ugandan context. Retrieved from http://www.ifpri.org/ publication/estimating-yield-food-crops-grownsmallholder-farmers.

Gourlay, S., Kilic, T., \& Lobell, D. (2017). Could the debate be over? Errors in farmer-reported production and their implications for the inverse scale-productivity relationship in Uganda. Washington, DC: World Bank. Retrieved from https://openknowledge.worldbank.org/handle/10986/ 28369.

Hagos, A., \& Geta, E. (2016). Review on small holders agriculture commercialization in Ethiopia: What are the driving factors to focused on? Development and Agricultural Economics, 8(4), 65-76. https://doi.org/10.5897/ JDAE2016.0718.

Jirström, M. (1996). In the wake of the Green Revolution: Environmental and socioeconomic consequences of intensive rice agriculture: The problems of weeds in Muda, Malaysia. Ph.D. dissertation (Avhandlingar 127). Lund.

Kassie, B. T., Van Ittersum, M. K., Hengsdijk, H., Asseng, S., Wolf, J., \& Rötter, R. P. (2014). Climate-induced yield variability and yield gaps of maize (Zea mays L.) in the Central Rift Valley of Ethiopia. Field Crops Research, 160(2014), 41-53. https://doi.org/10.1016/j.fcr.2014.02. 010.

Lipton, M. (2005). The family farm in a globalizing world: The role of crop science in alleviating poverty. Washington, DC: International Food Policy Research Institute.

Lobell, D. B., Azzari, G., Marshall, B., Gourlay, S., Jin, Z., Kilic, T., et al. (2018). Eyes in the sky, boots on the ground: Assessing satellite- and ground-based approaches to crop 
yield measurement and analysis in Uganda. Washington, DC: World Bank Group.

Lobell, D. B., Thau, D., Seifert, C., Engle, E., \& Little, B. (2015). A scalable satellite-based crop yield mapper. Remote Sensing of Environment, 164(2015), 324-333. https:// doi.org/10.1016/j.rse.2015.04.021.

MoFA-SRID. (2017). Agriculture in Ghana: Facts and figures 2016. Accra: Statistics, Research, and Information Directorate of the Ministry of Food and Agriculture.

Mueller, N. D., \& Binder, S. (2015). Closing yield gaps: Consequences for the global food supply. Environmental Quality and Food Security. Daedalus, 144(4), 45-56. https://doi.org/10.1162/DAED_a_00353.

Ray, D. K., Gerber, J. S., MacDonald, G. K., \& West, P. C. (2015). Climate variation explains a third of global crop yield variability. Nature Communications, 6(5989), 1-9. https://doi.org/10.1038/ncomms6989.

Reynolds, T. W., Anderson, L. C., Slakie, E., \& Gugerty, M. K. (2015). How common crop yield measures misrepresent productivity among smallholder farmers. Paper presented at the 29th international conference of agricultural economists, Milan, Italy.

Ronner, E., Franke, A. C., Vanlauwe, B., Dianda, M., Edeh, E., Ukem, B., et al. (2016). Understanding variability in soybean yield and response to P-fertilizer and rhizobium inoculants on farmers' fields in northern Nigeria. Field Crops Research, 186(2016), 133-145. https://doi.org/10. 1016/j.fcr.2015.10.023.

Rurangwa, E., Vanlauwe, B., \& Giller, K. E. (2018). Benefits of inoculation, $\mathrm{P}$ fertilizer and manure on yields of common bean and soybean also increase yield of subsequent maize. Agriculture, Ecosystems and Environment, 264(2018), 219-229. https://doi.org/10.1016/j.agee.2017.08.015.

Samberg, L. S., Gerber, J., Ramankutty, N., Herrero, M., \& West, P. (2016). Subnational distribution of average farm size and smallholder contributions to global food production. Environmental Research Letters, 11(2016), 124010. https://doi.org/10.1088/1748-9326/11/12/124010.

Sapkota, T. B., Jat, M. L., Jat, R. K., Kapoor, P., \& Stirling, C. (2016). Yield estimation of food and non-food crops in smallholder production systems. In T. S. Rosenstock, M. C. Rufino, K. Butterbach-Bahl, L. Wollenberg, \& M. Richards (Eds.), Methods for measuring greenhouse gas balances and evaluating mitigation options in smallholder agriculture (pp. 163-174). Cham: Springer.

Sheahan, M., \& Barrett, C. B. (2017). Ten striking facts about agricultural input use in Sub-Saharan Africa. Food Policy, 67(2017), 12-25. https://doi.org/10.1016/j.foodpol.2016. 09.010.

Sibley, M. A., Grassini, P., Thomas, E. N., Cassman, G. K., \& Lobell, B. D. (2014). Testing remote sensing approaches for assessing yield variability among maize fields. Agronomy Journal, 106(1), 24-32.
Singh, R. (2003). Use of satellite data and farmers eye estimate for crop yield modeling. New Delhi: Indian Agricultural Statistics Research Institute. Retrieved from http://agris. fao.org/agris-search/search.do?recordID=IN2004000941.

SRID-MoFA. (2013). Agriculture in Ghana: Facts and figures. Accra: Ministry of Food and Agriculture.

Srivastava, A. K., Mboh, C. M., Gaiser, T., Webber, H., \& Ewert, F. (2016). Effect of sowing date distributions on simulation of maize yields at regional scale: A case study in Central Ghana, West Africa. Agricultural Systems, 147(2016), 10-23. https://doi.org/10.1016/j.agsy.2016.05. 012.

Waddington, S. R., Li, X., Dixon, J., Hyman, G., \& de Vicente, M. C. (2010). Getting the focus right: Production constraints for six major food crops in Asian and African farming systems. Food Security, 2(1), 27-48. https://doi. org/10.1007/s12571-010-0053-8.

Wahab, I., Hall, O., \& Jirström, M. (2018). Remote sensing of yields: Application of UAV imagery-derived NDVI for estimating maize vigor and yields in complex farming systems in Sub-Saharan Africa. Drones, 2(3), 28. https:// doi.org/10.3390/drones2030028.

Wiggins, S. (2009). Can the smallholder model deliver poverty reduction and food security for a rapidly growing population in Africa?. Rome: Food and Agriculture Organization.

World Bank. (2003). Reaching the rural poor: A renewed strategy for rural development. Washington, DC: World Bank. Retrieved from http://documents.worldbank.org/ curated/en/227421468165890144/Reaching-the-ruralpoor-a-renewed-strategy-for-rural-development.

World Bank. (2008). World development report 2008: Agriculture for development. Washington, DC: World Bank.

World Bank. (2010). Global strategy to improve agricultural and rural statistics. Washington, DC: World Bank, United Nations, and Food and Agriculture Organization of the United Nations. Retrieved from www.fao.org/docrep/015/ am082e/am082e00.pdf.

Yengoh, G. T. (2012). Determinants of yield differences in small-scale food crop farming systems in Cameroon. Agriculture \& Food Security, 1(2012), 1-19.

Zhao, J., Shi, K., \& Wei, F. (2007). Research and application of remote sensing techniques in Chinese agricultural statistics. Paper presented at the fourth international conference on agricultural statistics, October 22-24 Beijing, China. www.stats.gov.cn/english/icas/papers/p020071017422431 720472.pdf.

Publisher's Note Springer Nature remains neutral with regard to jurisdictional claims in published maps and institutional affiliations. 